\title{
Caesarean section to prevent transmission of hepatitis B: A meta-analysis
}

\author{
Matthew S Chang MD¹, Sravanya Gavini MD¹, Priscila C Andrade PharmD², Julia McNabb-Baltar MD ${ }^{1}$
}

MS Chang, S Gavini, PC Andrade, J McNabb-Baltar. Caesarean section to prevent transmission of hepatitis B: A meta-analysis. Can J Gastroenterol Hepatol 2014;28(8):439-444.

BACKGROUND: Vertical transmission of hepatitis B virus (HBV) occurs in up to $10 \%$ to $20 \%$ of births.

OBJECTIVE: To assess whether Caesarean section, compared with vaginal delivery, prevents $\mathrm{HBV}$ transmission.

METHODS: A systematic review and meta-analysis was conducted. Two investigators independently searched PubMed, EMBASE and other databases for relevant studies published between 1988 and 2013. A manual search of relevant topics and major conferences for abstracts was also conducted. Randomized trials, cohort and case-control studies assessing the effect of delivery mode on vertical transmission of HBV were included. Studies assessing antiviral therapy and patients with coinfection were excluded. The primary outcome was HBV transmission rates according to delivery method.

RESULTS: Of the 430 studies identified, 10 were included. Caesarean section decreased the odds of HBV transmission by $38 \%$ compared with vaginal delivery (OR 0.62 [95\% CI 0.40 to 0.98]; $\mathrm{P}=0.04$ ) based on a random-effects model. Significant heterogeneity among studies was found $\left(\mathrm{I}^{2}=63 \% ; \mathrm{P}=0.003\right)$, which was largely explained by variation in hepatitis $\mathrm{B}$ immune globulin (HBIG) administration. Metaregression showed a significant linear association between the percentage of infants receiving HBIG per study and the log OR $(\mathrm{P}=0.005)$, with the least benefit observed in studies with $100 \% \mathrm{HBIG}$ administration. Subgroup analysis of hepatitis B e-antigen-positive women who underwent Caesarean section did not show a significant reduction in vertical transmission.

DISCUSSION: Caesarean section may protect against HBV transmission; however, convincing benefit could not be demonstrated due to significant study heterogeneity from variable HBIG administration, highlighting the importance of HBIG in HBV prevention.

CONCLUSION: More high-quality studies are needed before any recommendations can be made.

Key Words: Hepatitis; Hepatitis B immune globulin; Prophylaxis; Vaccination

Gour hundred million individuals are infected with hepatitis B virus (HBV) worldwide (1), which can lead to chronic hepatitis, cirrhosis and hepatocellular carcinoma. Most chronic infections are acquired perinatally via vertical transmission from the mother (2). HBV transmission has declined dramatically with the advent of universal screening of pregnant women in conjunction with passive and active immunization using hepatitis B immune globulin (HBIG) and HBV vaccine in the neonatal period. However, transmission remains as high as $10 \%$ to $20 \%$ in cases for which the mother has high viral DNA or positive hepatitis $\mathrm{B}$ e antigen $(\mathrm{HBe} \mathrm{Ag})$ levels $(3,4)$.

With HIV, Caesarean section has been shown to be efficacious in reducing vertical transmission from highly contagious mothers to their infants (5). In contrast, the effect of delivery mode on HBV transmission remains controversial $(6,7)$. Accordingly, we performed a

\section{La césarienne pour éviter la transmission de l'hépatite B : une méta-analyse}

HISTORIQUE : Dans $10 \%$ à $20 \%$ des accouchements, le virus de l'hépatite B (VHB) est transmis verticalement au nouveau-né.

OBJECTIF : Évaluer si la césarienne permet mieux d'éviter la transmission du VHB que l'accouchement vaginal.

MÉTHODOLOGIE : Une analyse systématique et une méta-analyse ont été menées. Deux chercheurs ont fait des recherches indépendantes dans PubMed, EMBASE et d'autres bases de données pour en extraire les études pertinentes publiées entre 1988 et 2013. On a également procédé à une recherche manuelle des sujets pertinents et des grands congrès et colloques afin d'en dépouiller les résumés. Les essais aléatoires, les études de cohortes et les études cas-témoins évaluant l'effet du mode d'accouchement sur la transmission verticale du VHB ont été inclus, mais les études évaluant la thérapie antivirale et les patients co-infectés ont été exclues. Le résultat primaire était le taux de transmission du VHB en fonction du mode d'accouchement.

RÉSULTATS : Dix des 430 études repérées ont été incluses. D'après un modèle à effets aléatoires, la césarienne réduisait de 38 \% le risque de transmission du VHB par rapport à l'accouchement vaginal ( $\mathrm{RC}$ 0,62 [95\% IC 0,40 à 0,98]; P=0,04). L'importante hétérogénéité entre les études $\left(\mathrm{I}^{2}=63 \% ; \mathrm{P}=0,003\right)$ s'expliquait en grande partie par la variation dans l'administration d'immunoglobuline de l'hépatite $B$ (IgHB). La méta-régression a démontré une association linéaire significative entre le pourcentage de nourrissons recevant de l'IgHB dans chaque étude et le logarithme du rapport de cotes $(P=0,005)$, le moins grand avantage étant observé dans des études où $100 \%$ des sujets avaient reçu de l'IgHB. L'analyse de sous-groupe des femmes porteuses de l'antigène e du VHB qui avaient subi une césarienne a établi que la transmission verticale ne diminuait pas de manière significative.

DISCUSSION : La césarienne protège peut-être contre la transmission du VHB, mais il été impossible de dégager des avantages convaincants en raison de l'hétérogénéité importante des études, attribuable à la variabilité dans l'administration d'IgHB, ce qui en fait ressortir l'importance pour prévenir le VHB.

CONCLUSION : Il faudra mener plus d'études de haute qualité avant de proposer des recommandations.

systematic review and meta-analysis to determine whether Caesarean section, compared with vaginal delivery, prevented transmission of HBV from infected mother to infant.

Data sources and searches

\section{METHODS}

The Cochrane Collaboration methodology was applied to search PubMed, EMBASE, LILACS, BIOSIS and the Cochrane databases for articles in English, Portuguese, French or Spanish from 1988 to 2013. In addition, references of relevant articles and abstracts from major conferences were manually searched. The following search terms were used as both keywords and medical subject heading terms, where applicable, after consultation with a reference librarian (Paul Bain

\footnotetext{
${ }^{1}$ Division of Gastroenterology, Hepatology, and Endoscopy, Brigham and Women's Hospital; ${ }^{2}$ Laboratory of Neuromodulation $\mathcal{E}$ Center for Clinical Research Learning, Spaulding Rehabilitation Hospital, Harvard Medical School, Boston, Massachusetts, USA

Correspondence: Dr Julia McNabb-Baltar, Division of Gastroenterology, Hepatology, and Endoscopy, Brigham and Women's Hospital, Harvard Medical

School, 75 Francis Street, Boston, Massachusetts 02115 USA. Telephone 617-525-8818, fax 617-566-0338, e-mail jmcnabb-baltar@partners.org

Received for publication March 26, 2014. Accepted June 25, 2014
} 
PhD, Harvard Medical School, Countway Library of Medicine, Boston, USA): Hepatitis B, Hepatitis B Virus, HBV, HBsAg, HBeAg, Caesarean Section, C section, "Mode of delivery", Pregnancy, Vertical Transmission, Perinatal Transmission, mother-to-child transmission, prevention. PubMed was searched for "Hepatitis B"[Mesh] OR "Hepatitis B virus"[Mesh] OR hepatitis b[tiab] OR HBV[tiab] OR HBsAg[tiab] OR HBeAg[tiab] AND (c section*[tiab] OR Caesarean*[tiab] OR "Caesarean Section"[Mesh] OR ECS[tiab]) and EMBASE was searched for 'hepatitis B'/exp OR 'hepatitis b':ti,ab OR HBV:ti,ab OR HBsAg:Ti,ab OR HBeAg:ti,ab, combined with 'Caesarean section'/exp OR caesarean*:ti,ab OR 'c section':ti,ab OR 'c sections':ti,ab OR ecs:ti,ab. Authors were contacted when data were ambiguous or missing.

\section{Study selection}

Inclusion criteria were determined a priori among the authors. Published and in-print randomized controlled trials, cohort studies and case-control studies were included. Overlapping studies, meta-analyses, systematic reviews, case reports/series, expert opinion, editorials, duplicates and animal studies were excluded. Eligible studies evaluated infants of pregnant mothers with chronic HBV infection, defined as positive hepatitis B surface antigen (8) who underwent Caesarean section or vaginal delivery. The intervention of interest was Caesarean section and the comparator was vaginal delivery. The outcome was vertical transmission of HBV. Studies in which the primary intervention was nucleos $(\mathrm{t})$ ide therapy were excluded.

\section{Data extraction and quality assessment}

Two authors performed the database search independently and compared their search results; another independent author reviewed discrepancies. Two authors independently conducted the data extraction process and disagreements were resolved by discussion between the two review authors. When agreement could not be reached, a third author acted as an arbiter. Additional data from one abstract presented at the annual European Association for the Study of the Liver conference (9) was obtained from the authors via e-mail (personal communication, Dr Sheng-Nan Lu, Kaohsiung Chang Gung Memorial Hospital, Kaohsiung, Taiwan). Data extraction from articles was performed using a form that was designed a priori to include study design, source country, exclusion criteria, number of infants and rates of vertical HBV transmission stratified according to Caesarean section and vaginal delivery, percentage of mothers who were $\mathrm{HBeAg}$ positive $(\mathrm{HBeAg}+)$, percentage of mothers that had HBV DNA $>10^{6}$ copies $/ \mathrm{mL}$, percentage of infants who received $\mathrm{HBIG}$ and dose administered, and percentage of infants who received HBV vaccine and schedule. During the data extraction process, the following details were added to the a priori form: elective versus urgent Caesarean section and use of assist devices during vaginal delivery, such as forceps or vacuum suction. During data extraction, the meta-estimate was changed from risk ratios to ORs for all studies because one study was a case control. The final search was performed on August 11, 2013.

The methodological quality of each study was assessed using the Newcastle-Ottawa Quality Assessment Scale (NOS), which is a method for assessing the quality of nonrandomized studies in metaanalyses (10). The NOS allocates a maximum of nine stars to assess three domains: quality of study group selection, comparability of intervention and nonintervention groups, and ascertainment of the exposure and outcome.

\section{Data synthesis and analysis}

The outcome of interest was HBV transmission to the infant, defined as either hepatitis B surface antigen positive or detectable HBV DNA level. The ORs of developing HBV in infants were obtained from the studies and stratified analyses were performed according to maternal HBV DNA levels $>10^{6}$ copies $/ \mathrm{mL}$ and $\mathrm{HBeAg}+$ status, which are measures of high viral infectivity. Also performed was an additional subgroup analysis of elective versus urgent Caesarean section because this may modify HBV transmission through excess blood exposure.
The primary meta-estimate - the OR of HBV transmission in Caesarean section compared with vaginal delivery - was calculated for all studies including 95\% CIs. Meta-analyses using both fixed-effects (11) and a random-effects models were conducted (12). It was anticipated that there would be high level of heterogeneity among the studies; results were reported using the random-effects model. Binary outcomes are presented as OR with 95\% CI. Pooled ORs and 95\% CI were determined using a Mantel-Haenszel random-effects model. An OR of $<1$ favoured Caesarean section as having a preventive effect on HBV transmission while an OR of $>1$ indicated that Caesarean section was harmful and increased HBV transmission. The point estimate of the $\mathrm{OR}$ was considered to be statistically significant at the $\mathrm{P}<0.05$ level if the $95 \%$ CI did not include the value 1 .

Statistical between-study heterogeneity was assessed using the $\mathrm{I}^{2}$ test to measure the extent of inconsistency among the results and $\chi^{2}$ test, with statistical significance set at $\mathrm{P}<0.05$. Publication bias was assessed using funnel plot (13). An asymmetric funnel plot suggests publication bias or a systematic difference between smaller and larger studies ('small study effects') or the use of an inappropriate effect measure. Publication bias was also evaluated by the Duval and Tweedie trim-and-fill method (14). To evaluate the impact of each individual study, sensitivity analyses using a one-study-removed method were performed. Temporal trends and secular changes were assessed with the cumulative analysis approach.

Because HBV transmission rates are directly influenced by prophylaxis with HBIG and vaccination, subgroup analyses were performed in an attempt to explain possible sources of heterogeneity and used the test for interaction ( $\chi^{2}$ statistic) to estimate differences between groups. Unrestricted maximum likelihood random effects meta-regression was applied to percentage of HBIG administered as a continuous variable to evaluate for the impact of HBIG on HBV transmission rates. For all tests, a two-tailed $\mathrm{P}<0.05$ was considered to be statistically significant. All analyses were performed in Comprehensive Meta Analysis Version 2.0 (Biostat, USA). The study is reported according to the Meta-analysis Of Observational Studies in Epidemiology (MOOSE) group reporting guidelines (15). All authors had access to the study data, and reviewed and approved the final manuscript.

\section{Study selection}

\section{RESULTS}

The search strategy identified 430 articles, of which 420 were excluded and 10 were included for analysis (Figure 1). Of the 10 studies included, eight were full-text articles $(6,7,16-21)$ and two were major society meeting abstracts $(9,22)$. One abstract (22) was found in EMBASE. The other abstract (9) was identified by searching the reference lists of the retrieved full-text articles.

Study characteristics are described in Table 1 . Nine studies were retrospective cohort studies and one was a case-control study. The primary meta-estimate measured was the OR of HBV transmission from mothers to newborns among women who underwent Caesarean section $(n=2352)$ compared with vaginal delivery $(n=2739)$, yielding a total of 5091 newborns. The HBV transmission rate was $8 \%$ overall: $5 \%$ (116 of 2352) for mothers who underwent Caesarean section and $10 \%$ (283 of 2739) for those who underwent vaginal delivery. Three studies were conducted in $\mathrm{HBeAg}+$ women exclusively, one study did not specify, and the remaining studies had mixed $\mathrm{HBeAg}+$ and negative populations (range $25 \%$ to $55 \% \mathrm{HBeAg}+$ ). Prophylaxis rates with HBIG and HBV vaccination of infants varied across studies: three reported $100 \%$ prophylaxis with HBIG and vaccination, one did not mention prophylaxis rate, and the remaining studies reported a wide range (HBIG $51 \%$ to $76 \%$, vaccination $1 \%$ to $100 \%$ ). Four studies differentiated urgent from elective Caesarean section; only one study described whether instrumentation (forceps or suction) was used during delivery. Only four studies explicitly stated their exclusion criteria; all four excluded HIV, three excluded HCV coinfection and three excluded any form of recent HBV therapy (nucleos[t]ide analogues or 


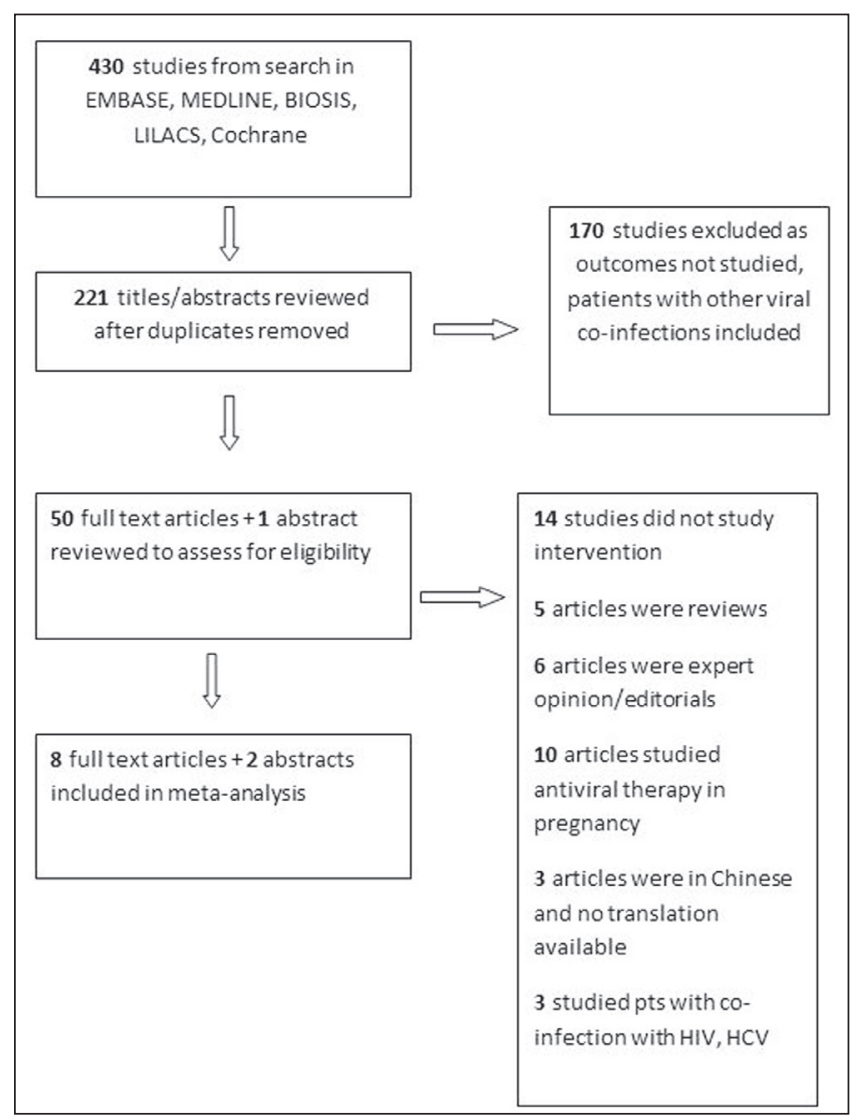

Figure 1) Flow diagram of the study search and selection process. HCV Hepatitis C virus; pts Patients

interferon). Seven studies were conducted in China, two in Taiwan and one in India. According to the NOS, nine studies were high quality (scores between 6 and 9) and one study was low quality (score 4); however, only three of the studies controlled for potential confounders.

\section{Meta-analysis}

Seven studies demonstrated decreased odds of HBV transmission, of which three were statistically significant, while three demonstrated increased odds of HBV transmission, but none were statistically significant (Figure 2). The overall meta-analysis demonstrated a statistically significant decrease in HBV vertical transmission with Caesarean section compared with vaginal delivery, with an OR of 0.62 (95\% CI [0.40 to 0.978]; $\mathrm{P}=0.04)$. As expected, there was significant heterogeneity among the studies ( $Q$ test $25.58 ; P=0.003 ; I^{2}=63 \%$ ).

A one-study-removed analysis was generally consistent with the overall finding that Caesarean section was associated with a reduction in HBV transmission, although this resulted in having the upper limit of the 95\% CI cross 1 (null) in seven of 10 cases (Wang et al [20] [OR 0.57 [95\% CI 0.35 to 0.93], Chen et al [16] [OR 0.57 [95\% CI 0.35 to 0.92] and Hu et al [6] [OR 0.55 [95\% CI 0.36 to 0.83], forest plot not shown). A cumulative analysis demonstrated a persistent trend toward a protective effect of Caesarean section on HBV transmission as studies were added to the model over time, but this did not consistently reach statistical significance (data not shown). This finding may have been due to the publication of five studies in the same year. When including only high-quality studies (NOS $\geq 6$ ) and excluding Chen et al (16) (NOS 4), Caesarean section still reduced HBV transmission (OR 0.57 [95\% CI 0.35 to 0.92]). However, this effect was no longer significant when limiting the analysis to cohort studies (excluded Guo et al [18], which was a case control study) (OR 0.70 [95\% CI 0.44 to 1.11]) or when considering only high-quality cohort studies (excluding both Chen et al [16] and Guo et al [18]) (OR 0.635 [95\% CI 0.38 to 1.07]) (forest plots not shown).

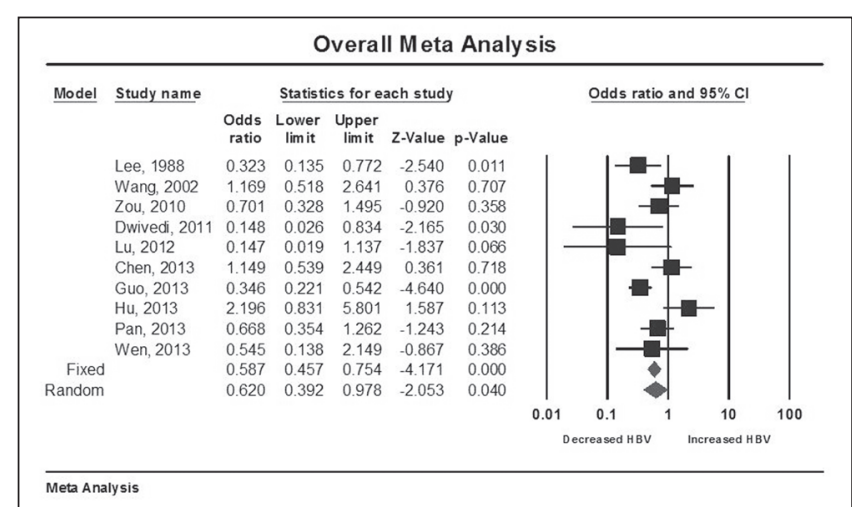

Figure 2) Meta-analysis of hepatitis B virus transmission risk with Caesarean section versus vaginal delivery

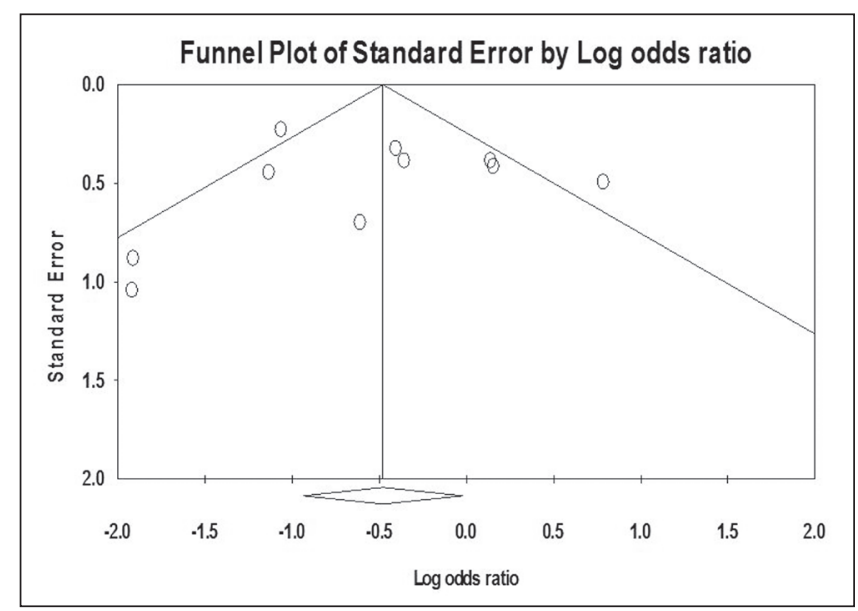

Figure 3) Funnel plot of standard error according to hepatitis B virus transmission risk

A funnel plot was only mildly asymmetric, suggesting that smaller studies at the right margin of the plot, favouring an increase in HBV transmission with Caesarean section, may be missing (Figure 3). The Duval and Tweedie trim-and-fill method (14) did not add any studies, indicating that publication bias was not a significant factor.

Of the studies with $<100 \%$ of HBIG administration in infants, the study by $\mathrm{Hu}$ et al (6) collected HBV prophylaxis administration data primarily using surveys one to seven years after childbirth, rendering the study vulnerable to recall bias. Additionally, the HBV transmission rate in the vaginal delivery group was disproportionately lower than expected (2\%). While this may, in part, be due to the low $\mathrm{HBeAg}+$ prevalence of $25 \%$, the $\mathrm{HBV}$ transmission rate was still lower than Wen et al (21), which had a similar $\mathrm{HBeAg}+$ prevalence of $27 \%$, but a much higher HBV transmission rate of $4 \%$ in the vaginal delivery group, suggesting that the population in $\mathrm{Hu}$ et al (6) study may be fundamentally different from the other study populations. To better account for this persistent heterogeneity, a meta-regression was performed to evaluate a potential linear relationship between the percentage of patients administered HBIG and the log OR of HBV transmission. While there was no association in the initial model $(\mathrm{P}=0.78$ [model not shown]), a subsequent meta-regression excluding Hu et al (6) (Figure 4) revealed a significant linear relationship, such that the $\log \mathrm{OR}$ increased by 0.02 times for each percentage point increase in HBIG administered $(\mathrm{P}=0.005)$ This confirmed the expected clinical finding that HBV transmission decreased as HBIG use approached $100 \%$, accounting for the underlying heterogeneity among studies. 


\begin{tabular}{|c|c|c|c|c|c|c|c|c|c|c|}
\hline 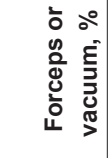 & 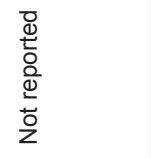 & $\stackrel{m}{\sim}$ & 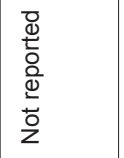 & 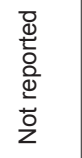 & 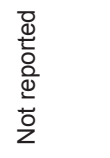 & 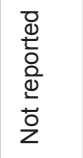 & 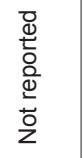 & 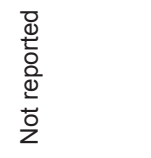 & 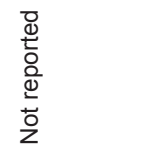 & 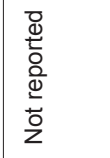 \\
\hline 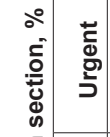 & 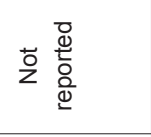 & 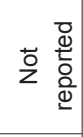 & $\approx$ & $\stackrel{\circ}{\leftarrow}$ & 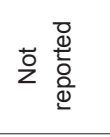 & 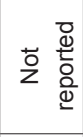 & 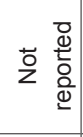 & 0 & 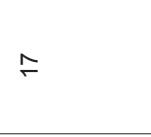 & 旁 \\
\hline 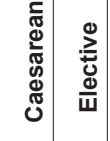 & 흘 & 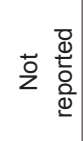 & m & $\mp$ & 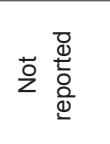 & 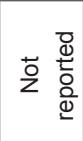 & 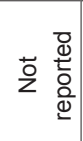 & กิ & $\stackrel{\text { }}{\circ}$ & 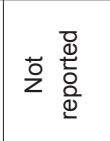 \\
\hline 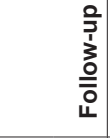 & 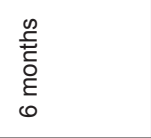 & 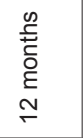 & 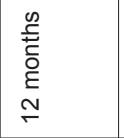 & 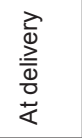 & 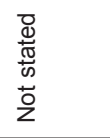 & 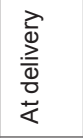 & $\underset{d}{\stackrel{c}{d}}$ & 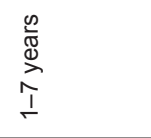 & 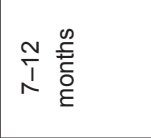 & 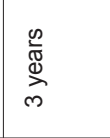 \\
\hline 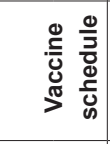 & 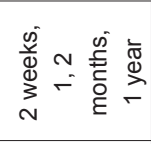 & 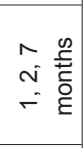 & 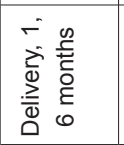 & 总 & 苋 & 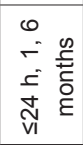 & 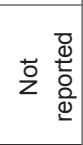 & $\begin{array}{l}0 \\
0 \\
0 \\
0 \\
0 \\
0 \\
0 \\
0\end{array}$ & 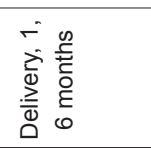 & 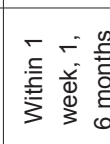 \\
\hline 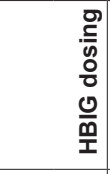 & 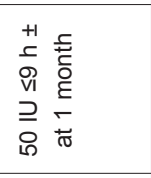 & $\frac{}{\circ}$ & 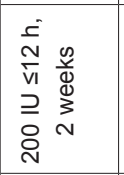 & 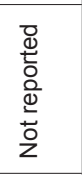 & 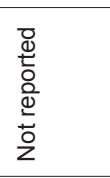 & 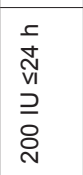 & 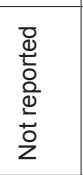 & 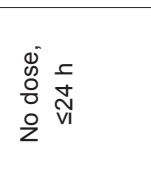 & 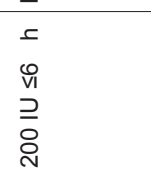 & 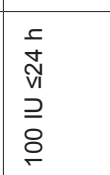 \\
\hline 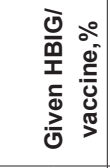 & $\frac{8}{0}$ & 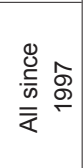 & 웅 & 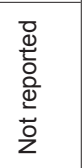 & $\frac{\sqrt{\frac{1}{2}}}{\frac{1}{2}}$ & $\begin{array}{l}8 \\
\frac{8}{2} \\
\frac{8}{0}\end{array}$ & $\overline{8}$ & $\frac{8}{\stackrel{8}{2}}$ & $\begin{array}{l}8 \\
\frac{8}{2} \\
\frac{1}{2}\end{array}$ & 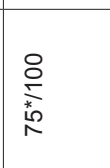 \\
\hline 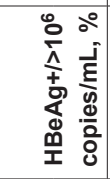 & ò & 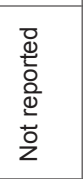 & $\stackrel{1}{\circ}$ & $\frac{1}{\frac{d}{d}}$ & $\stackrel{\circ}{\circ}$ & 胥 & $\frac{1}{\infty}$ & 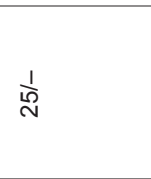 & 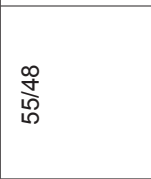 & $\frac{1}{N}$ \\
\hline 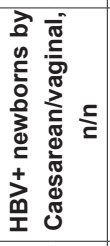 & $\frac{\mathscr{D}}{6}$ & $\stackrel{10}{\risingdotseq}$ & 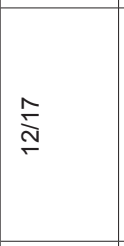 & $\stackrel{10}{\lambda}$ & $\stackrel{\infty}{\stackrel{\infty}{\xi}}$ & $\stackrel{+}{\stackrel{N}{N}}$ & $\frac{N}{\stackrel{N}{N}}$ & 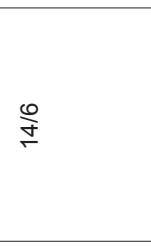 & 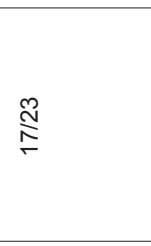 & 命 \\
\hline 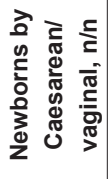 & 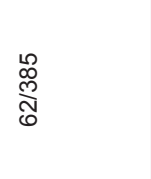 & 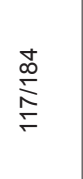 & $\begin{array}{l}\stackrel{\infty}{\infty} \\
\stackrel{\infty}{N} \\
\stackrel{\infty}{N}\end{array}$ & 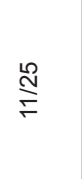 & $\frac{\mathbb{N}}{\sum_{j}^{2}}$ & $\frac{\mathfrak{m}}{\infty}$ & 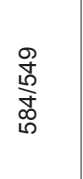 & $\begin{array}{l}\bar{o} \\
\stackrel{N}{\$ D} \\
\text { No }\end{array}$ & 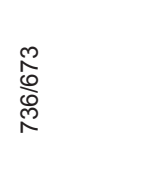 & 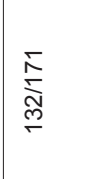 \\
\hline 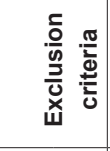 & tัo & 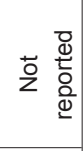 & 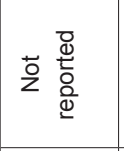 & 它 & 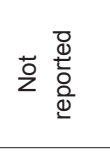 & 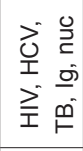 & 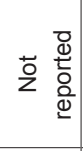 & 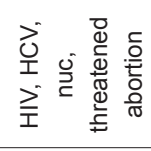 & 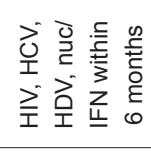 & 主 \\
\hline 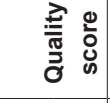 & $\frac{\mathscr{O}}{\theta}$ & $\stackrel{\Omega}{R}$ & $\stackrel{Q}{R}$ & $\frac{R}{N}$ & $\frac{\mathscr{\rho}}{\infty}$ & $\stackrel{g}{f}$ & $\stackrel{R}{R}$ & $\frac{a}{N}$ & $\stackrel{\rho}{\sigma}$ & $\frac{\Omega}{\infty}$ \\
\hline 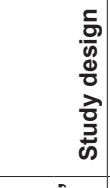 & 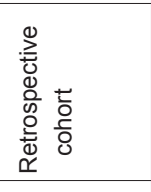 & 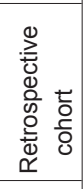 & 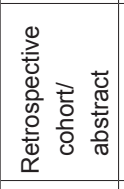 & 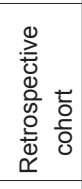 & 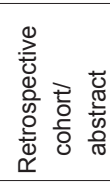 & 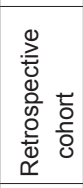 & 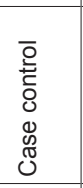 & 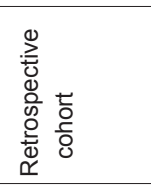 & 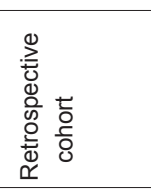 & 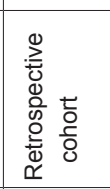 \\
\hline 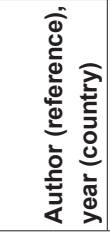 & 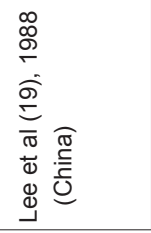 & 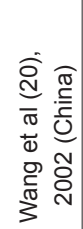 & 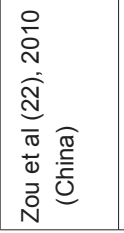 & 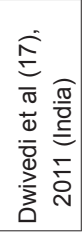 & 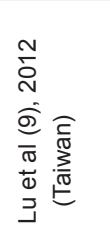 & 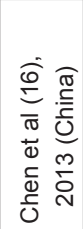 & 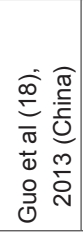 & 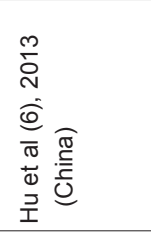 & 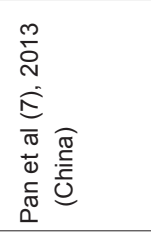 & 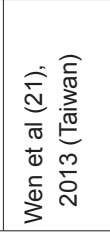 \\
\hline
\end{tabular}


A subgroup analysis stratified according to $100 \%$ HBV vaccination use found only a modest decrease in heterogeneity among studies that had $100 \%$ vaccination rates ( $Q$ test $9.86 ; P=0.08 ; I^{2}=49 \%$ [data not shown]). Further stratification within individual studies according to delivery type among women who received appropriate prophylaxis was not possible given the insufficient data. In three studies, data regarding rates of $\mathrm{HBV}$ transmission in $\mathrm{HBeAg}+$ women, high risk for transmission, specified by delivery type were available. A separate analysis was performed that suggested a reduction in HBV transmission with Caesarean section but was not statistically significant (OR 0.71 [95\% CI 0.47 to 1.08 ]; low heterogeneity, $\mathrm{Q}=0.18 ; \mathrm{P}=0.92 ; \mathrm{I}^{2}=0 \%$ ).

\section{DISCUSSION}

Using a random-effects pooled meta-analysis, we detected a statistically significant decrease in the overall odds of HBV transmission in women who underwent Caesarean section compared with vaginal delivery. In contrast, a majority of the individual studies had point estimates favouring a reduction in HBV transmission with Caesarean section, but were inconclusive because the 95\% CI crossed 1. Our findings are consistent with the findings of meta-analyses before 2012: one was inconclusive and another found a benefit with Caesarean section $(23,24)$. We were able to include six additional studies (3738 newborns) that have been published since 2012, making our meta-analysis the largest and most robust to date.

There was significant heterogeneity among studies, which was largely explained by varying rates of HBIG prophylaxis. In the adjusted meta-regression model, as HBIG use approached 100\%, the protective benefit of Caesarean section appeared to decrease, confirming the importance of HBIG in preventing vertical transmission.

Despite demonstrating a benefit in HBV transmission, our findings should be interpreted within the context of the study limitations, particularly given the high heterogeneity and deficits in primary study quality. Although NOS scores were generally high, several of the studies were missing key study details, as depicted in the evidence table (Table 1), and only two studies controlled for confounders such as high viral levels and nucleos(t)ide use. Most studies were conducted in China, with a varying $\mathrm{HBeAg}+$ prevalence and, therefore, may be less generalizable to other countries. Two of the more recent studies $(9,22)$ were only available in abstract form, which significantly limits indepth analysis. Follow-up periods in several studies spanned decades when HBV prophylaxis was not yet standard of care and many infants may not have received it; this may have elevated the risk for transmission in these studies. HBV transmission also differs in cases of elective compared with urgent Caesarean section for which there is potential for more bleeding and, thus, a greater opportunity for viral transmission. However, this level of detail was not available in most of the studies.

Interpretation of our study findings in the clinical setting is challenging because Caesarean section carries its own complex set of risks. HBIG administration and HBV vaccination should be the first-line measure based on established guidelines (1). All women diagnosed with HBV should be referred to a provider experienced in the management of chronic liver disease (8). Our meta-analysis demonstrated that Caesarean section may offer additional protection against vertical transmission of HBV from the mother to the newborn, but the exact degree of benefit remains uncertain and is heavily influenced by HBIG administration rates. Any protective benefit from Caesarean section most likely occurs in higher-risk mothers, namely those who are $\mathrm{HBeAg}+$ or have persistently elevated DNA levels despite nucleos(t)ide therapy before delivery, and should be studied further. It would be difficult to perform an adequately powered study, which would require 475 women with high viremia who failed nucleos(t)ide therapy, for each delivery method (vaginal versus Caesarean) to have $80 \%$ power to detect a decrease in HBV transmission rates from $10 \%$ to $5 \%$. Additionally, differences in HBV transmission rates among women undergoing elective versus urgent Caesarean section are still unknown and also require further investigation. Based on fair evidence, we

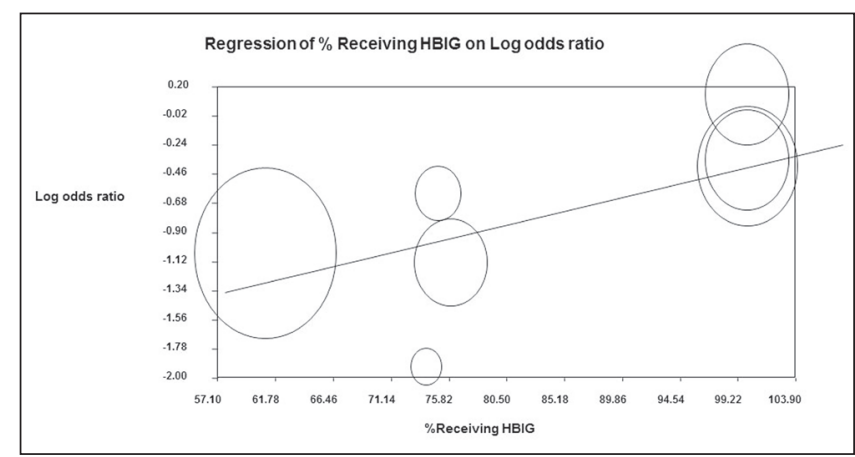

Figure 4) Adjusted meta-regression of percent of women receiving hepatitis $\mathrm{B}$ immune globulin (HBIG) and log OR after removal of the study by $\mathrm{Hu}$ et al (6) (size of circles are proportional to study sample size)

cannot make formal recommendations for or against the use of Caesarean section to prevent transmission of HBV (Grade C). Ultimately, more definitive studies, such as large population-based cohort studies or planned meta-analyses that include 100\% HBIG and vaccination use, are needed to confirm our findings before Caesarean section can be adopted in clinical practice as a preventive measure against vertical transmission of HBV.

ACKNOWLEDGEMENTS: The authors thank Michael Stoto PhD and Deanna Alexis Carere MA MS CGC CCGC (Harvard School of Public Health) for their meta-analysis guidance.

DISCLOSURES: PCA is an employee of Johnson \& Johnson Medical, Brazil. The remaining authors have no financial disclosures or conflicts of interest to declare. This study was not funded.

\section{REFERENCES}

1. Keeffe EB, Dieterich DT, Han SH, et al. A treatment algorithm for the management of chronic hepatitis $\mathrm{B}$ virus infection in the United States: 2008 update. Clin Gastroenterol Hepatol 2008;6:1315-41.

2. Pan CQ, Duan ZP, Bhamidimarri KR, et al. An algorithm for risk assessment and intervention of mother to child transmission of hepatitis B virus. Clin Gastroenterol Hepatol 2012;10:452-9.

3. Han GR, Cao MK, Zhao W, et al. A prospective and open-label study for the efficacy and safety of telbivudine in pregnancy for the prevention of perinatal transmission of hepatitis $B$ virus infection. J Hepatol 2011;55:1215-21.

4. Pan CQ, Han GR, Jiang HX, et al. Telbivudine prevents vertical transmission from HBeAg-positive women with chronic hepatitis B. Clin Gastroenterol Hepatol 2012;10:520-6.

5. Read JS, Newell MK. Efficacy and safety of cesarean delivery for prevention of mother-to-child transmission of HIV-1. Cochrane Database Syst Rev 2005:CD005479.

6. Hu Y, Chen J, Wen J, et al. Effect of elective cesarean section on the risk of mother-to-child transmission of hepatitis B virus. BMC Pregnancy Childbirth 2013;13:119.

7. Pan CQ, Zou HB, Chen Y, et al. Cesarean section reduces perinatal transmission of hepatitis B virus infection from hepatitis B surface antigen-positive women to their infants.

Clin Gastroenterol Hepatol 2013;11:1349-55.

8. Lok AS, McMahon BJ. Chronic hepatitis B: Update 2009. Hepatology 2009;50:661-2.

9. Lu SN, Wu CH, Ou CY, et al. Outcomes of combination of hepatitis $B$ immunoglobuin and hepatitis $B$ vaccination in high-risk newborns born to HBeAg-positive mothers. J Hepatol 2012;56:S31-2.

10. Wells G, Shea B, O'Connell D, et al. The New Castle-Ottawa Scale (NOS) for assessing the quality of non-randomized studies in metaanalysis. <www.ohri.ca/programs/clinical_epidemiology/oxford.asp> (Accessed August 16, 2013).

11. Demets DL. Methods for combining randomized clinical trials: Strengths and limitations. Stat Med 1987;6:341-50. 


\section{Chang et al}

12. DerSimonian R, Laird N. Meta-analysis in clinical trials. Controlled Clin Trials 1986;7:177-88.

13. Egger M, Davey Smith G, Schneider M, et al. Bias in meta-analysis detected by a simple, graphical test. BMJ 1997;315:629-34.

14. Duval S, Tweedie R. Trim and fill: A simple funnel-plot-based method of testing and adjusting for publication bias in metaanalysis. Biometrics 2000;56:455-63.

15. Stroup DF, Berlin JA, Morton SC, et al. Meta-analysis of observational studies in epidemiology: A proposal for reporting. Meta-analysis Of Observational Studies in Epidemiology (MOOSE) group. JAMA 2000;283:2008-12.

16. Chen Y, Wang L, Xu Y, et al. Role of maternal viremia and placental infection in hepatitis B virus intrauterine transmission. Microbes Infect 2013;15:409-15.

17. Dwivedi M, Misra SP, Misra V, et al. Seroprevalence of hepatitis B infection during pregnancy and risk of perinatal transmission. Indian J Gastroenterol 2011;30:66-71.

18. Guo Z, Shi XH, Feng YL, et al. Risk factors of HBV intrauterine transmission among $\mathrm{HBs} \mathrm{Ag}$-positive pregnant women. J Viral Hepatit 2013;20:317-21.
19. Lee SD, Lo KJ, Tsai YT, et al. Role of caesarean section in prevention of mother-infant transmission of hepatitis $B$ virus. Lancet 1988;2:833-4.

20. Wang J, Zhu Q, Zhang X. Effect of delivery mode on maternalinfant transmission of hepatitis B virus by immunoprophylaxis. Chinese Med J 2002;115:1510-2.

21. Wen WH, Chang MH, Zhao LL, et al. Mother-to-infant transmission of hepatitis B virus infection: Significance of maternal viral load and strategies for intervention. J Hepatol 2013;59:24-30.

22. Zou H, Chen Y, Duan Z, et al. A retrospective study for clinical outcome of caesarean section on perinatal transmission of hepatitis $\mathrm{B}$ virus in infants born to $\mathrm{HBeAg}$ positive mothers with chronic hepatitis B (CHB). Hepatology 2010;(Suppl):235A. (Abst)

23. Wang HH, Wang ZP. [A Meta analysis: Mother to infant transmission of hepatitis $B$ virus via different combined immunoprophylaxis delivery modes]. Zhonghua yu fang yi xue za zhi [Chinese journal of preventive medicine] 2010;44:221-3.

24. Yang J, Zeng XM, Men YL, et al. Elective caesarean section versus vaginal delivery for preventing mother to child transmission of hepatitis B virus - a systematic review. Virol J 2008;5:100. 


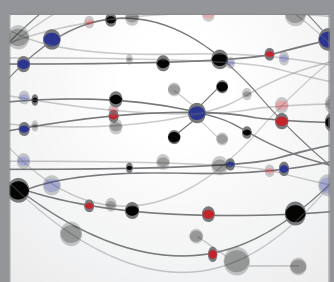

The Scientific World Journal
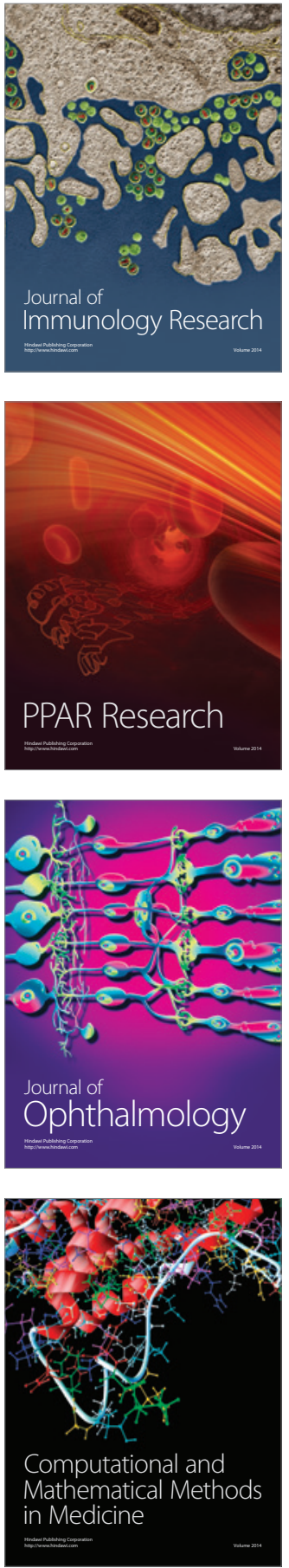

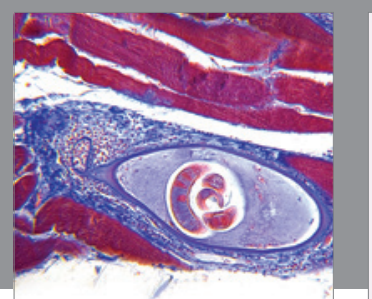

Gastroenterology Research and Practice

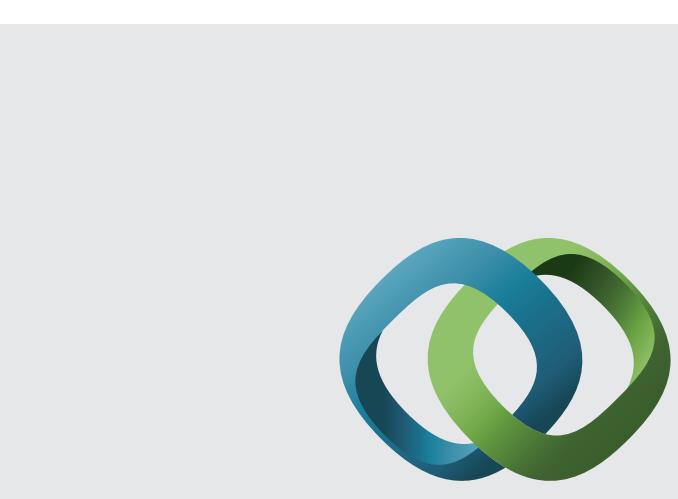

\section{Hindawi}

Submit your manuscripts at

http://www.hindawi.com
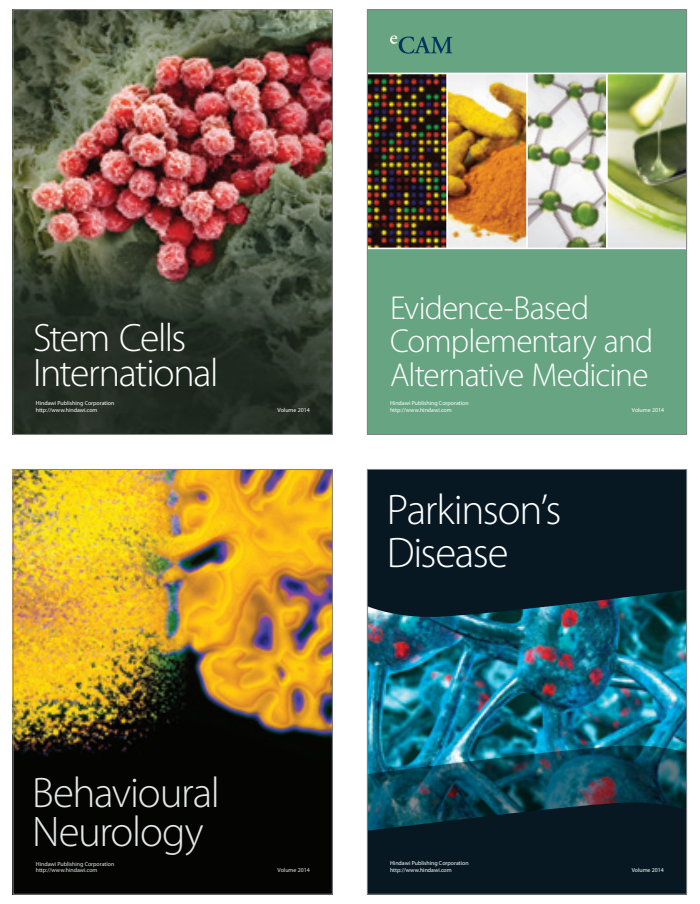
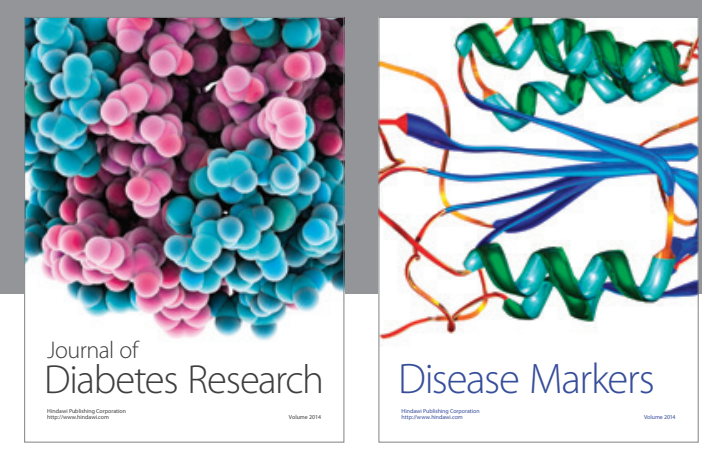

Disease Markers
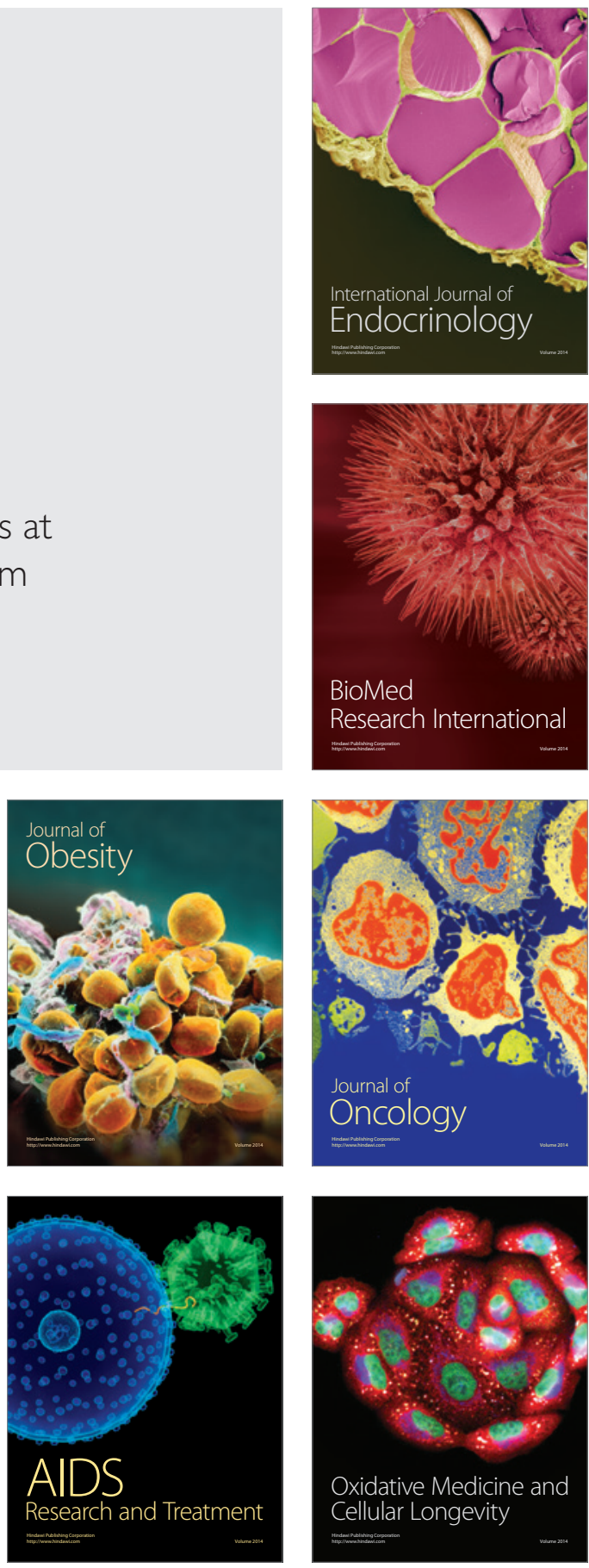